\title{
Factors influencing the rate of preantral and antral growth of mouse ovarian follicles in vitro
}

\author{
P. L. Nayudu* and S. M. Osborn \\ Reproductive Biology Unit, Royal Women's Hospital, 132 Grattan St, Carlton, Victoria, 3053 , \\ Australia
}

\begin{abstract}
Summary. The development of a culture system for individual mouse ovarian follicles using a low concentration of homologous serum, human follicle-stimulating hormone (hFSH) and a simple combination of growth factors is reported. Preantral follicles, $150 \mu \mathrm{m}$ in diameter, with thecal cells attached were isolated mechanically. After 6-7 days on a Millicell membrane, a high proportion of the preantral follicles cultured individually with hFSH grew to morphologically normal large antral follicles (400$500 \mu \mathrm{m}$ in diameter) with high oestradiol secretion. Without hFSH, the follicles grew to approximately $275 \mu \mathrm{m}$ diameter in 6 days, but did not form antra or secrete oestradiol. The growth trajectory (overall pattern of growth formed by daily measurements of diameter) of each follicle was recorded and used as a measurement of response to experimental variation of culture conditions. The rapidly growing follicles were morphologically normal, but those that grew more slowly showed some abnormality or atresia and secreted less oestradiol.

Follicles cultured in groups without being in direct contact with each other showed much poorer growth than those grown individually, but the inhibition was not uniform and some follicles grew larger than others in the group. Follicles that contacted each other directly in culture tended to fuse into one mass and their growth was substantially inhibited. Even under these conditions, one follicle often continued to grow slowly while the others degenerated. Such alteration of growth patterns suggests interfollicular paracrine control and may be a means of three-dimensional spacing of follicle growth within the ovary, as well as part of the mechanism of follicle selection. The doseresponse curve based on the mean growth trajectory of follicles cultured individually, produced increasing rates of growth with $12 \cdot 5-100 \mathrm{miu} h \mathrm{hSH} \mathrm{ml}{ }^{-1}$. Higher concentrations of hFSH did not increase growth rate further, but oestradiol secretion continued to increase with increasing hFSH up to the maximum used $\left(2000 \mathrm{miu} \mathrm{ml}^{-1}\right)$.
\end{abstract}

Keywords: ovarian follicle; antral development; growth rate; mouse

\section{Introduction}

Detailed investigations into the mechanisms of ovarian follicular development have been restricted by the lack of a defined culture system that can sustain normal follicular growth through all stages of development from preantral to large antral and ovulation of a functionally normal oocyte.

Culture of isolated granulosa cells has added greatly to knowledge of the function of these cells, but, because the isolated follicle cells do not proceed through normal development when released from the stage-specific sequences of the follicular environment (Epstein-Almog \& Orly, 1985; Terada et al., 1985; Jia \& Hsueh, 1986; Carson et al., 1989), the results are not directly applicable to

\footnotetext{
*Present address: Abteilung Reproduktionsbiologie, Deutsches Primatenzentrum GmbH, Kellnerweg 4, D-3400
} Göttingen, Germany. 
intact follicles. Follicle cells have been shown to influence each other when two types are cultured together and to undergo some differentiation, but they cannot proceed through normal developmental sequences without the intact follicular structure (Nekola \& Nalbandov, 1971; McNatty et al., 1980; Eppig \& Downs, 1987; Gore-Langton \& Daniel, 1990).

There have been few reports on follicle culture. Antral follicle culture has mainly involved short-term incubation ( 2 days or less) of large antral follicles either for measuring steroid secretion (Bogovich \& Richards, 1982; Laufer et al., 1982; Vanhems et al., 1982; Carlsson et al., 1985; Zimmerman et al., 1985) or for achieving intrafollicular oocyte maturation for production of live offspring (Moor \& Trounson, 1977; Fukui et al., 1987). Short-term incubations of isolated cumulus-granulosa-oocyte complexes have resulted in the growth and meiotic maturation of oocytes in vitro (Eppig \& Downs, 1987) and embryonic development resulting in some normal offspring in mice (Schroeder \& Eppig, 1984; Eppig \& Schroeder, 1989) and in large animals (Staigmiller \& Moor, 1984; Fukui et al., 1988; Goto et al., 1988).

A number of attempts have been made to produce antral development from preantral follicles in culture, but with limited success. Baker \& Neal (1974) maintained human ovarian cortical fragments for 12 days without growth. Torrance et al. (1989) cultured enzymically digested primary mouse follicles in collagen gel for more than a week, achieving growth, but no antral development. Roy \& Greenwald reported limited antral development from mechanically dissected stage-6 follicles (Roy \& Greenwald, 1989), but not from enzymically digested smaller follicles. Qvist et al. (1990) have shown antral development (after 6-12 days) from mechanically isolated clumps of preantral mouse follicles, similar to that reported by Roy \& Greenwald (1989), but from an apparently smaller starting size.

Oocytes from intact cultured small follicles have not been shown to have normal developmental capacity. Follicle growth achieved in culture has been limited, and the starting material has been somewhat heterogeneous, all of which limit their usefulness in the quantitative study of follicle development. To overcome the limitations of the previous systems, we aimed to (a) determine the in vitro requirements for optimal follicle growth from preantral to large antral stages, using starting material of closely controlled quality and size from as early a stage as possible; (b) achieve rapid growth to periovulatory size, ideally within the time span of a mouse cycle (4-5 days; Hogan et al., 1986); and (c) to assess critically the morphology of the follicles in comparison with in vivo follicles.

\section{Materials and Methods}

\section{Follicle isolation and blood collection}

Female prepubertal mice (Swiss random bred: Monash University Central Animal House, Melbourne, Australia) 25 days old, were used as a source of ovaries and of blood for culture. These mice were chosen because of their large natural litters. Animals were anaesthetized with diethyl ether and blood was sampled from the heart, allowed to clot in washed Eppendorf tubes, and centrifuged in an Eppendorf single speed centrifuge for $5 \mathrm{~min}$. The serum was collected and used immediately or stored at $-80^{\circ} \mathrm{C}$ for use when the medium was changed. Serum with visible haemolysis was discarded.

Ovaries were removed aseptically and placed in Leibovitz L-15 (ICN-Flow, Irvine, UK) supplemented with glutamine $\left(2 \mathrm{mmol}^{-1}\right)$ and bovine serum albumin fraction V (BSA $3 \mathrm{~g} \mathrm{l}^{-1}$ ) (Sigma, St Louis, MO, USA). Each pair of ovaries was dissected in a 30-mm diameter Falcon plastic Petri dish (Becton Dickinson, Sumpter, SC, USA). Follicles were isolated in Leibovitz L-15 medium under a dissection microscope. Initially, the ovaries were teased into clumps of follicles using two specially constructed steel microforks, each with two curved prongs, which allowed clumps of follicles to be separated without damage. Individual follicles from these clumps were isolated at $\times 40$ magnification with two 28-gauge needles attached to $1 \mathrm{ml}$ syringes. The mean diameter (including only the structures within the follicle wall) of each isolated follicle was measured with a calibrated ocular micrometer. For most experiments, follicles of about $150 \mu \mathrm{m}$ diameter were chosen. Care was taken to retain a layer of thecal and some stromal cells around the isolated follicle. Pasteur pipettes used to transfer follicles were coated with BSA to prevent sticking.

The follicles were transferred as rapidly as possible to alpha Minimal Essential Medium (MEM) (Gibco-BRL,

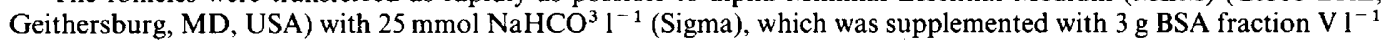
and glutamine $\left(2 \mathrm{mmol}^{-1}\right)$ in a humidified chamber with a continuous flow of $5 \% \mathrm{CO}_{2}$ in air within an incubator also 
gassed with $5 \% \mathrm{CO}_{2}$ in air, but not humidified. When a sufficient number of follicles had been collected, they were graded. The criteria used for acceptable quality were a central spherical oocyte, high density of granulosa cells, distinct follicle wall and a distinct layer of thecal cells.

\section{Follicle culture}

Follicles (initially in alpha MEM + BSA) were placed in Millicell-CM culture plate inserts (12 mm diameter) (Millipore, Bedford, MA, USA) in groups or individually, depending on the experiment. The inserts were in Nunclon four-well culture plates (AS Nunc, Roskilde, Denmark). Medium was placed only within the Millicell inserts. The Biopore membrane base of the inserts retained the medium as long as the plastic well remained dry, allowing an increased surface area for the medium to facilitate gas exchange.

The medium providing the conditions for maximum antral development was alpha $\mathrm{MEM}$ with $25 \mathrm{mmol} \mathrm{NaHCO}_{3}$ $1^{-1}, 0.1 \mathrm{~g}$ penicillin-G $\mathrm{l}^{-1}$ (Sigma, St Louis, MO, USA) and $0.05 \mathrm{~g}$ streptomycin $\mathrm{l}^{-1}$ (Sigma) and supplemented with $5 \%$ mouse serum, $5 \mu \mathrm{g}$ bovine insulin $\mathrm{ml}^{-1}$ (Sigma), $10 \mu \mathrm{g}$ human transferrin $\mathrm{ml}^{-1}$ (Sigma), $50 \mathrm{ng}$ insulin-like growth factor- $1 \mathrm{ml}^{-1}$ (Boehringer Mannheim GmbH, Mannheim, Germany), 2 mmol glutamine $\mathrm{I}^{-1}$ (ICN-Flow), and $\geqslant 100$ iu human follicle-stimulating hormone (hFSH) $\mathrm{ml}^{-1}$ (Boehringer). FSH and luteinizing hormone (LH) immunoactivity was verified by the Amerlite FSH and LH assays (Amersham, UK). Boehringer hFSH ( $1 \mu \mathrm{g}=4 \cdot 5 \mathrm{iu}) \mathrm{had}$ $12 \cdot 3$ miu LH per 1000 miu FSH.

Unless otherwise stated, all experiments used this medium with one follicle per well, $1000 \mathrm{miu} \mathrm{hFSH} \mathrm{ml}^{-1} \mathrm{and} \mathrm{a}$ change of medium every other day. Each variable was tested with a minimum of eight follicles per experiment and each culture was repeated two or three times. Except where individual follicle growth patterns are displayed, most of the results are means of eight follicles from one experiment, with the exception of the FSH dose-response, when more follicles were used to calculate the mean response. The diameters of the follicles were measured every day as described. The thecal cells were not included in the diameter until day 3 because initially the layer was thin and the boundary of theca and stroma not distinct. On day 3, half the contribution of the theca and stroma was included, and on subsequent days the entire theca was included in the diameter measurement.

The supplements were made as stock solution and stored in volumes adequate for one experiment at $-80^{\circ} \mathrm{C}$. Medium was sterilized with $0 \cdot 2 \mu \mathrm{m}$ filters after the addition of the supplements immediately before use. In addition to the supplements mentioned, fetal calf serum (Commonwealth Serum Laboratories, Melbourne, Australia) was also tested.

\section{Fixation and processing of follicles}

Follicles were dissected from ovaries and fixed immediately or after various periods of culture. Some whole ovaries were also fixed and sectioned. The fixation was in 3.5\% glutaraldehyde (TAAB Laboratories, UK) in cacodylate buffer (sodium cacodylate, $0 \cdot 1 \mathrm{~mol} \mathrm{1}{ }^{-1}$; Agar Aids, UK) at pH 7.4 at room temperature for $1 \mathrm{~h}$. Follicles were then fixed in $1 \%$ osmium tetroxide (Johnson Matthey Chemical, UK) in the same cacodylate buffer for $1 \mathrm{~h}$ and dehydrated through graded alcohols and finally acetone. They were embedded in Spurr's resin (Polysciences, USA) and cured at $60^{\circ} \mathrm{C}$ for $24 \mathrm{~h}$. Serial $0.5 \mu \mathrm{m}$ sections were cut through the follicles, which were mounted on glass slides and stained with $1 \%$ methylene blue (Schmid GmbH, Germany) in 1\% sodium tetraborate (Nayudu et al., 1989).

\section{Steroid assays}

Concentrations of oestradiol and progesterone were measured using a modified solid-phase radioimmunoassay kit from Diagnostic Products Co-op. (Los Angeles, CA, USA). The main changes introduced were standards at lower concentrations, incubations for $2 \mathrm{~h}$ at room temperature with shaking, instead of the standard $3 \mathrm{~h}$ without shaking, and the addition of steroid-free serum (Bioclone, Australia) to correct for matrix effects. Control culture fluid was added to the standard and quality control. The assay sensitivities were $0.01 \mathrm{nmol} 1^{-1}$ for oestradiol, and $0 \cdot 1 \mathrm{nmol} 1^{-1}$ for progesterone. Both assays were highly specific for the steroid of interest. For the oestradiol assay, the highest cross-reactivities were $1.8 \%$ for ethinyl oestradiol and $1.1 \%$ for oestrone and $0.69 \%$ for $17 \beta$-oestradiol-3 $\beta$-Dglucuronide. For the progesterone assay, the highest crossreactivities were $2 \cdot 4 \%$ for 11 -deoxycortisol, $2 \cdot 0 \%$ for $20 \alpha$ dihydroprogesterone, $1.7 \%$ for 11 -deoxycorticosterone and $1.3 \%$ for $5 \beta$-pregnan-3,20-dione. The oestradiol assay showed intra-assay and interassay coefficients of variation of 5.3 and $6.4 \%$, respectively; for progesterone, the coefficients were 7.2 and $7 \cdot 9 \%$, respectively. The culture fluid was diluted $1: 6$ with $0 \cdot 1$ mol phosphate buffer $1^{-1}$ at pH $7 \cdot 4$, for assay, and $50 \mu \mathrm{l}$ of steroid-free serum was added to each assay tube.

\section{Results}

\section{Conditions fundamental to the growth of follicles in vitro}

Mechanical dissection of the follicles and the use of a culture vessel in which cells do not attach (Millicell) were essential for the success of the culture system. These two factors allowed the follicle 
structure to stay intact, including the surrounding thecal cells. The stage and condition of the freshly dissected follicles was also critical. A follicle was considered to be suitable as starting material for culture (Fig. 1) if it had a spherical oocyte with a nucleus of normal appearance and with no irregularities in the cytoplasm and no degeneration of other cells apparent. Granulosa cells were two layers in transition to three (140-160 $\mu$ m diameter), with some spaces between cells where there were only two layers. A thin layer (1-3 cells depth) of flattened thecal cells was also present.

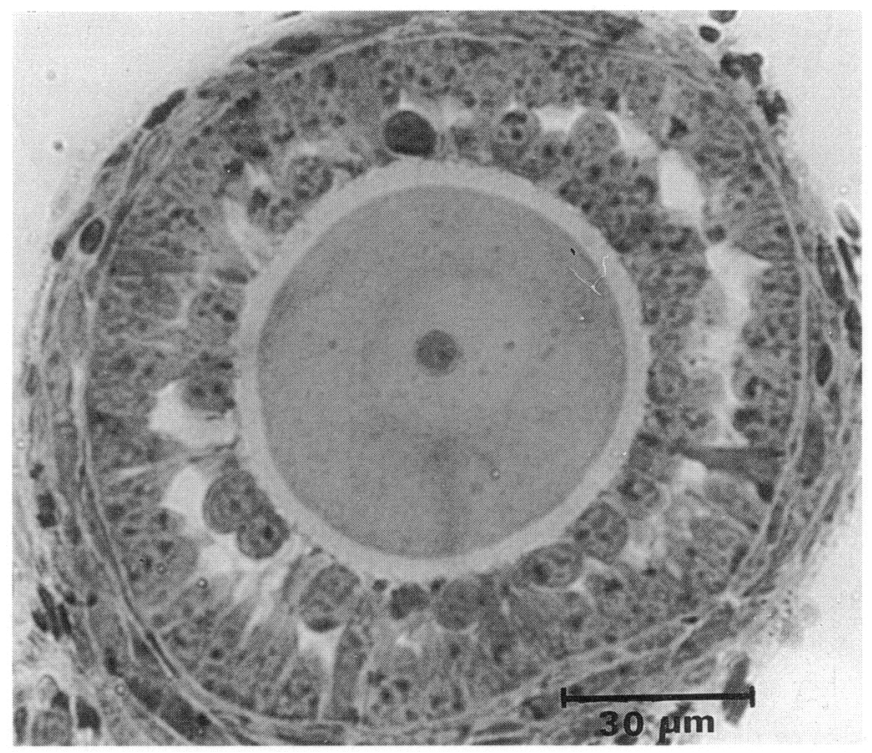

Fig. 1. Example of a healthy mechanically dissected follicle $140-150 \mu \mathrm{m}$ in diameter from the ovary of a 25-day-old Swiss random-bred mouse, suitable as starting material for culture.

Mouse serum was essential in the culture, and $5 \%$ produced the best growth. Follicle growth in the presence of 1000 miu FSH with $5 \%$ mouse serum was compared with growth in $5 \%$ fetal calf serum or $4 \mathrm{mg} \mathrm{BSA} \mathrm{ml}^{-1}$. Only mouse serum, in these experiments obtained from the ovary donor or from other female mice of the same age and strain, produced follicle morphology similar to that observed in vivo. The mean diameters on day 6 of culture were $425 \mu \mathrm{m}$ with mouse serum and $350 \mu \mathrm{m}$ with fetal calf serum. Thecal cells did not proliferate normally and the granulosa cell density appeared thin. Follicles grown with BSA as the protein source rapidly lost normal follicle morphology and grew as a solid mass of cells, which produced more oestradiol on day 4 of culture $\left(71 \cdot 6 \pm 54 \cdot 5(\mathrm{SD}) \mathrm{nmol} 1^{-1}\right)$ than follicles grown in mouse serum $\left(10 \cdot 3 \pm 10 \cdot 3 \mathrm{nmol}^{-1}\right)$.

\section{Factors influencing growth in vitro}

\section{Change of medium}

For follicles grown 1 per well, the growth improvement associated with medium change was dramatic (Fig. 2). Without a change of medium, follicles grew only for 4 or 5 days, reaching a maximum of $250 \mu \mathrm{m}$ before extruding their oocytes, even in the presence of $1000 \mathrm{miu} \mathrm{FSH} \mathrm{ml}{ }^{-1}$. Follicle growth was greatly improved by a change of medium on day 2 , two follicles $(25 \%)$ reaching $400 \mu \mathrm{m}$ diameter by day 6 . A change of medium on day 4 as well as day 2 slightly improved mean growth after day 4 and a higher proportion $(50 \%)$ attained diameters $\geqslant 400 \mu \mathrm{m}$ by day 6 .

\section{Number of follicles per well}

Even in the presence of high concentrations of FSH (1000 miu ml $\left.{ }^{-1}\right)$ and with medium changed every other day, an important factor in the quality of growth was the number of follicles in the well 


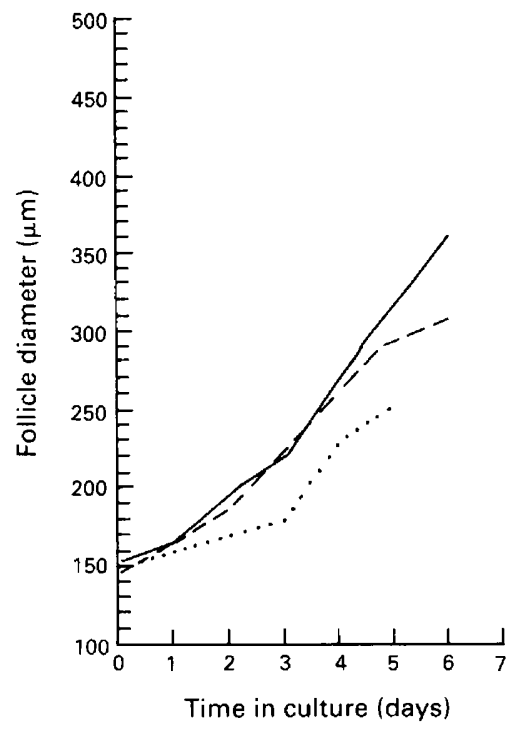

Fig. 2. Mean growth rate of mouse follicles grown individually in the presence of $1000 \mathrm{miu}$ human follicle-stimulating hormone $\mathrm{ml}^{-1}$, with no change in medium during 6 days of culture $(\cdots)$, medium removed and replaced with fresh medium on day 2 of culture (-- ), medium removed and replaced with fresh medium on days 2 and 4 of culture $(-)$. For means in all figures, $n=8$; medium change on days 2 and 4 chosen as standard.

and whether they were in direct contact. Follicles that clumped together tended to fuse and form a single mass. With two follicles, one always grew faster, but they did not attain sizes greater than $325 \mu \mathrm{m}$. If more than two follicles were in direct contact, most follicles degenerated, leaving perhaps one to grow to small antral size.

Where multiple follicles were not in direct contact with each other, the follicles did not degenerate, but most grew slowly, the rate accelerating towards the end of their growth period. However, one or two in a group of eight usually grew more rapidly. In one example (Fig. 3a), only one follicle reached $400 \mu \mathrm{m}$ by day 6 , whereas the others were only $250-300 \mu \mathrm{m}$. In contrast, a high proportion $(\geqslant 75 \%)$ of follicles grown singly (Fig. $3 \mathrm{~b}$ ) attained a diameter of $\geqslant 350 \mu \mathrm{m}$ by day 6 .

\section{Effect of follicle size at the start of culture}

Follicles of three mean starting diameters $(125,150$ and $175 \pm 10 \mu \mathrm{m})$ were compared for their growth in culture in the presence of $1000 \mathrm{miu}$ FSH ml ${ }^{-1}$ under optimal conditions (Fig. 4). Although certain $125 \mu \mathrm{m}$ follicles grew at a rate similar to that for $150 \mu \mathrm{m}$ follicles, they took longer to begin the rapid growth phase and therefore achieved a smaller final diameter (after 6 days in culture). Others had erratic growth profiles, and those without theca or with inadequate theca did not grow at all. The most rapidly growing $150 \mu \mathrm{m}$ follicles increased, on average, $60-75 \mu \mathrm{m} \mathrm{day}^{-1}$ from day 1 to reach a maximum diameter of $425-450 \mu \mathrm{m}$ by day 6 . Follicles starting their in vitro growth at $175 \mu \mathrm{m}$ diameter tended to have the most rapid early growth (days $0-2$ ) although the subsequent growth rate was similar to that of $150 \mu \mathrm{m}$ follicles.

\section{Differential effect of hFSH on preantral and antral growth}

FSH had a positive effect on follicle preantral growth but an obvious and repeatable difference in mean diameter tended not to occur until the second day of culture (Fig. 5a) in response to $1000 \mathrm{miu}$ hFSH ml ${ }^{-1}$ compared with no hFSH, there was no difference in growth on day 1 and a mean difference of $25 \mu \mathrm{m}$ on day 2 between the treatment groups. The hFSH dose-response curve (Fig. 6a) suggests that follicle growth from day 0 to day 2 of culture may increase with increasing doses of FSH to the highest dose tested. However, the same relationship does not hold for growth 


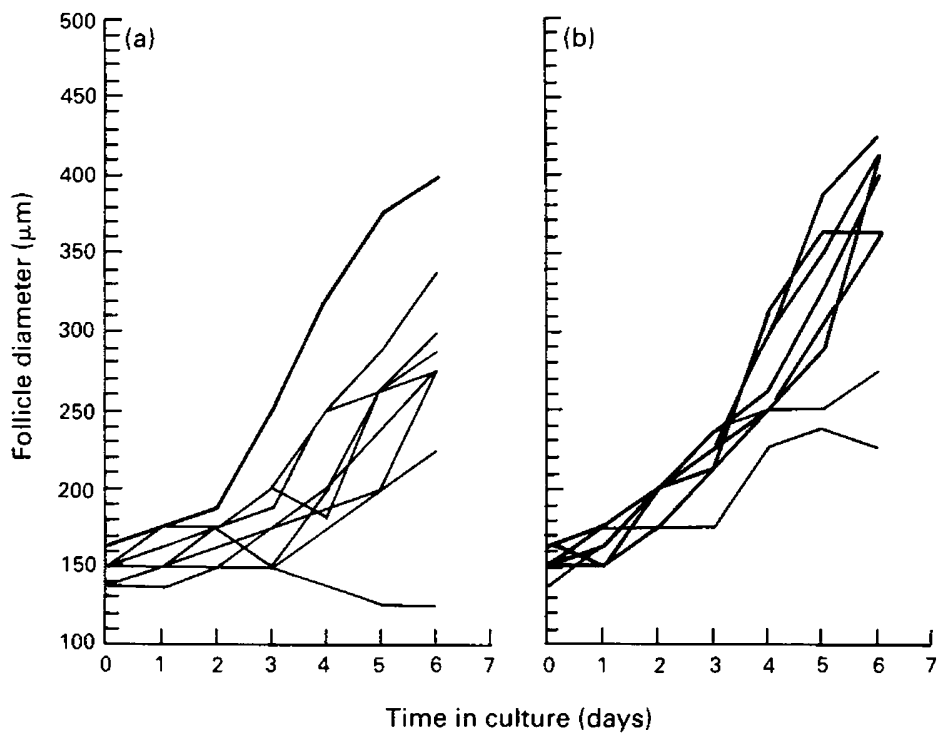

Fig. 3. Growth of individual mouse follicles cultured in the presence of $1000 \mathrm{miu}$ folliclestimulating hormone $\mathrm{ml}^{-1}$. (a) Nine per well, but without direct contact, and (b) one per well.

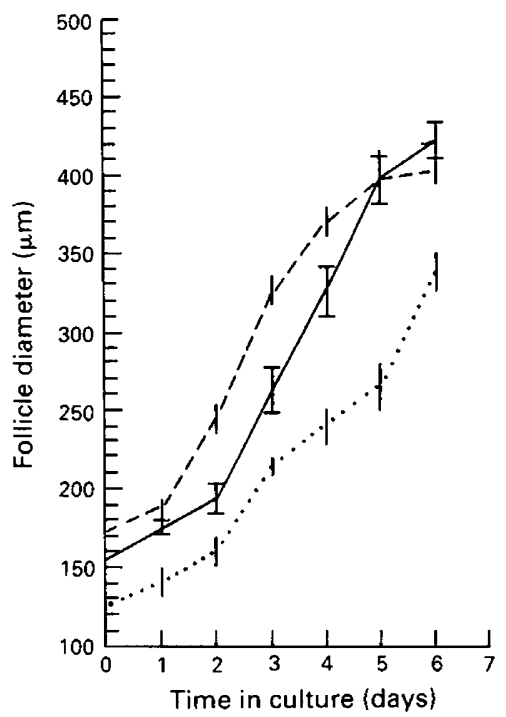

Fig. 4. Growth rates (mean \pm SEM) of mouse follicles of starting size $175 \mu \mathrm{m}(--), 150 \mu \mathrm{m}$ $(-), 125 \mu \mathrm{m}(\cdots)$ in the presence of 1000 miu human follicle-stimulating hormone $\mathrm{ml}^{-1}$; $150 \mu \mathrm{m}$ was chosen as the standard size.

rates after day 2 , which did not increase beyond $100 \mathrm{miu}$ hFSH $\mathrm{ml}^{-1}$. The importance of FSH during the first two days of growth to the growth on subsequent days was demonstrated by culturing in medium lacking hFSH from day 2 onwards (Fig. 5b). The response of the follicles varied: some ceased to grow, but most continued their growth at relatively normal rates for three more days and antra were formed. 

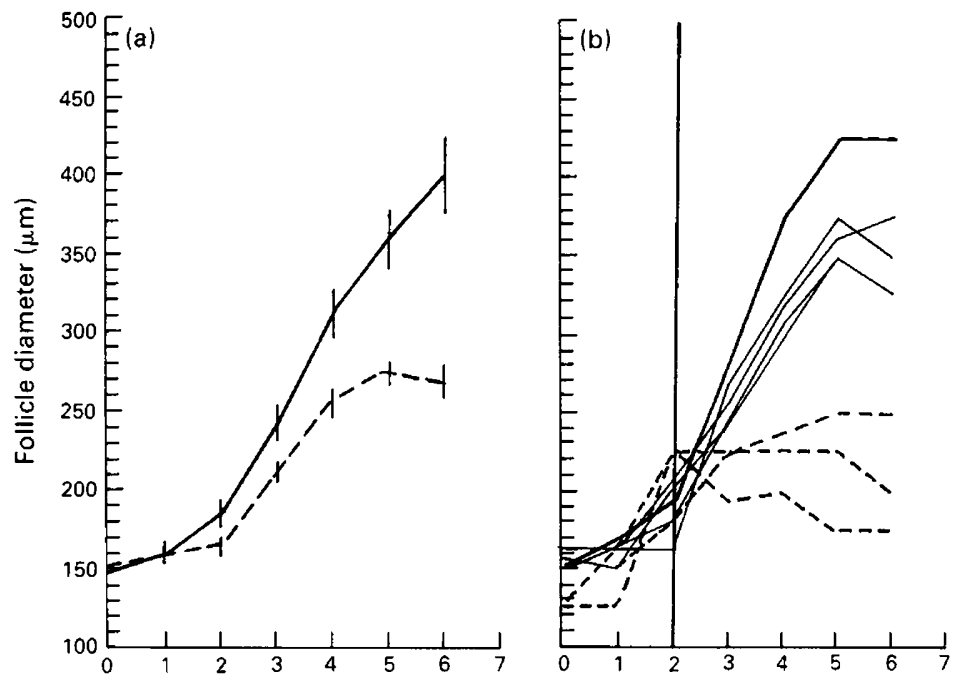

Time in culture (days)

Fig. 5. (a) Growth rates (mean \pm SEM) of mouse follicles in the absence $(---)$ or presence $(-)$ of 1000 miu human follicle-stimulating hormone (hFSH) $\mathrm{ml}^{-1}$. (b) Effect of lack of hFSH in culture from day 2.

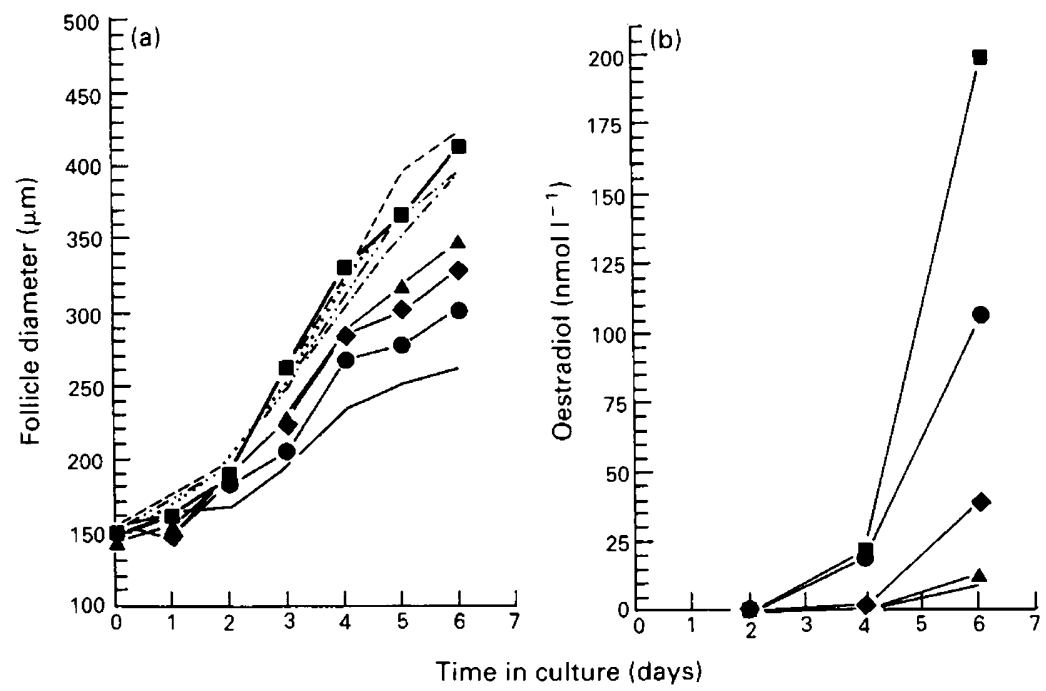

Fig. 6. Dose-response for human follicle-stimulating hormone (hFSH): (a) effect of dose on mean mouse follicle growth ( $n$ and SEM shown in Table 1); $0(-), 12.5(\bullet), 25(\bullet), 50(\Delta)$, and $100(\mathbb{D}) \mathrm{miu} h \mathrm{hSH} \mathrm{ml}^{-1}$. Higher doses which did not produce further increases in overall growth rate are shown with broken lines $(250[-\cdot-], 500[\cdots], 1000[--], 2000[-\cdots-])$. (b) Oestradiol secretion into the medium for $100(-), 250(\Delta), 500(\bullet), 1000(\bullet)$ and $2000(\square)$ miu hFSH $\mathrm{ml}^{-1}$.

\section{Response to FSH dose}

Follicles were cultured individually in a range of FSH concentrations to determine a dose-response based on follicle growth rate and oestradiol secretion and to establish the optimal concentration of hFSH for follicle growth. The growth rates increased as the dose of FSH increased 
from 0 to $100 \mathrm{miu} \mathrm{m}^{-1}$ (Fig. 6a, Table 1). Beyond $100 \mathrm{miu} \mathrm{ml}^{-1}$, further increases in FSH did not produce increased follicle growth. However, in contrast to the plateau in growth, oestradiol secretion, which was still quite low at $100 \mathrm{miu} \mathrm{FSH} \mathrm{ml}{ }^{-1}$, increased twenty-fold (from 10 to $200 \mathrm{nmol} \mathrm{l}^{-1}$ ) on day 6 with doses of $100 \mathrm{miu} \mathrm{FSH} \mathrm{ml}{ }^{-1}$ to $2000 \mathrm{miu} \mathrm{ml}^{-1}$ (Fig. 6b). Progesterone concentrations did not increase in response to FSH dose and remained $<30 \mathrm{nmol} 1^{-1}$ on day 6 for all doses.

Table 1. Effect of human follicle-stimulating hormone (hFSH) on mean follicle diameter $(\mu \mathrm{m} \pm \mathrm{SEM})$ for 6 days of culture (Swiss random-bred mice)

\begin{tabular}{|c|c|c|c|c|c|c|c|c|}
\hline \multirow{2}{*}{$\begin{array}{l}\text { hFSH dose } \\
\left(\text { miu ml }^{-1}\right)\end{array}$} & \multirow[b]{2}{*}{$n$} & \multicolumn{7}{|c|}{ Number of days in culture } \\
\hline & & 0 & 1 & 2 & 3 & 4 & 5 & 6 \\
\hline \multirow[t]{2}{*}{0} & 22 & $154 \cdot 0$ & $162 \cdot 5$ & $166 \cdot 8$ & $195 \cdot 0$ & $235 \cdot 3$ & $251 \cdot 5$ & $262 \cdot 5$ \\
\hline & & \pm 1.8 & $\pm 2 \cdot 0$ & \pm 4.0 & $\pm 5 \cdot 5$ & $\pm 5 \cdot 3$ & \pm 4.0 & \pm 4.8 \\
\hline \multirow[t]{2}{*}{$12 \cdot 5$} & 6 & $\overline{149} \cdot 0$ & 147.3 & $\overline{182} \cdot 3$ & $\overline{205} \cdot 0$ & 267.8 & $\overline{277 \cdot 5}$ & 301.8 \\
\hline & & $\pm 2 \cdot 0$ & \pm 7.5 & $\pm 8 \cdot 3$ & $\pm 8 \cdot 3$ & \pm 6.5 & \pm 6.3 & \pm 7.8 \\
\hline \multirow[t]{2}{*}{$25 \cdot 0$} & 7 & 152.8 & 147.3 & 190.0 & 226.0 & $284 \cdot 8$ & $300 \cdot 8$ & 328.5 \\
\hline & & $\begin{array}{l}+2.5 \\
\end{array}$ & $+6 \cdot 3$ & $\begin{array}{r}+5.3 \\
\end{array}$ & \pm 9.3 & \pm 8.0 & \pm 8.0 & \pm 10.0 \\
\hline \multirow[t]{2}{*}{$50 \cdot 0$} & 13 & $\overline{14} 3 \cdot 3$ & $\overline{154} \cdot 8$ & 186.5 & $\overline{228} \cdot 3$ & 285.5 & $\overline{31} 18.8$ & 348.5 \\
\hline & & +3.5 & $+6 \cdot 3$ & \pm 7.5 & \pm 10.3 & $\pm 11 \cdot 3$ & \pm 12.8 & \pm 14.5 \\
\hline \multirow[t]{2}{*}{100} & 10 & 148.8 & $161 \cdot 3$ & $188 \cdot 3$ & $262 \cdot 3$ & $331 \cdot 3$ & 367.0 & 413.3 \\
\hline & & \pm 2.8 & $\pm 2 \cdot 0$ & $\pm 4 \cdot 5$ & \pm 7.5 & \pm 9.0 & $\begin{array}{r}+9.0 \\
\end{array}$ & \pm 8.5 \\
\hline \multirow{2}{*}{250} & 9 & $\overline{155.5}$ & $\overline{172} \cdot 3$ & $200 \cdot 8$ & $\overline{25} 1 \cdot 5$ & $304 \cdot 3$ & 350.0 & 393.0 \\
\hline & & $\pm 5 \cdot 5$ & \pm 1.8 & \pm 8.0 & \pm 13.5 & \pm 17.5 & \pm 13.0 & \pm 11.5 \\
\hline \multirow[t]{2}{*}{500} & 13 & 147.0 & 168.3 & $200 \cdot 3$ & $255 \cdot 3$ & $322 \cdot 3$ & 371.5 & 390.0 \\
\hline & & \pm 4.3 & $\pm 4 \cdot 3$ & \pm 5.8 & $\pm 9 \cdot 8$ & \pm 12.5 & \pm 14.5 & \pm 13.3 \\
\hline \multirow[t]{2}{*}{1000} & 13 & 154.5 & $\overline{17} 6.3$ & 193.3 & $\overline{262} \cdot 0$ & 325.0 & $396 \cdot 3$ & 422.0 \\
\hline & & +0.8 & $\begin{array}{r}+5.3 \\
\end{array}$ & $\begin{array}{r}+9.0 \\
\end{array}$ & $\begin{array}{r}+14.0 \\
\end{array}$ & +15.8 & \pm 15.3 & \pm 11.3 \\
\hline \multirow[t]{2}{*}{2000} & 15 & $\overline{152.5}$ & $\overline{171} \cdot 3$ & 95.8 & 246.0 & 311.8 & $364 \cdot 3$ & 397.0 \\
\hline & & $\pm 2 \cdot 5$ & $\pm 3 \cdot 3$ & $\pm 7 \cdot 5$ & $\pm 9 \cdot 3$ & \pm 10.8 & $\pm 10 \cdot 5$ & $\pm 9 \cdot 5$ \\
\hline
\end{tabular}

\section{Variation of individual follicle growth within treatment}

Within each treatment, a range of follicle growth profiles occurred. A small proportion did not respond to hFSH and either did not grow at all or grew only to the size of the follicles cultured without hFSH $(275 \mu \mathrm{m}$ or less by day 6$)$. Figure $3 \mathrm{~b}$ shows an example of the range of individual growth in the standard treatment. Seventy-five per cent of the follicles are classified as having responded to $\mathrm{hFSH}$, final diameters ranging from approximately 360 to $425 \mu \mathrm{m}$. Of the follicles that responded to hFSH with differing growth rates, those that grew more slowly also secreted lower concentrations of oestradiol.

Morphological studies also showed differences between the rapidly growing and therefore larger follicles and those that grew more slowly. For example, two follicles grew rapidly during 7 days of culture in the presence of $1000 \mathrm{miu} \mathrm{hFSH} \mathrm{ml}^{-1}$ (Fig. 7a and b). The appearance and size of these follicles is similar to that of a healthy large pre-ovulatory follicle before the LH surge; a freshly dissected follicle of approximately $150 \mu \mathrm{m}$ diameter is shown in Fig. 7c at the same magnification for comparison.

A higher magnification of the follicle in Fig. 7a reveals an oocyte of generally normal appearance (Fig. 8a, but slightly oval shape) with undulations of the nuclear membrane suggesting early signs of germinal vesicle breakdown. The cytoplasm appears uniform and the cumulus is composed of a thick layer of cells. The granulosa cells appear healthy and organized, and an apparently normal (with the exception of a lack of blood capillaries) theca interna and externa are present surrounding a well-defined follicle wall (Fig. 8b). The appearance of a follicle grown without hFSH (Figs $7 \mathrm{f}$ and $8 \mathrm{c}$ ) is very different: these follicles increased in diameter during culture by proliferation of granulosa and thecal cells, but no antrum was formed and pycnotic cells were present. 

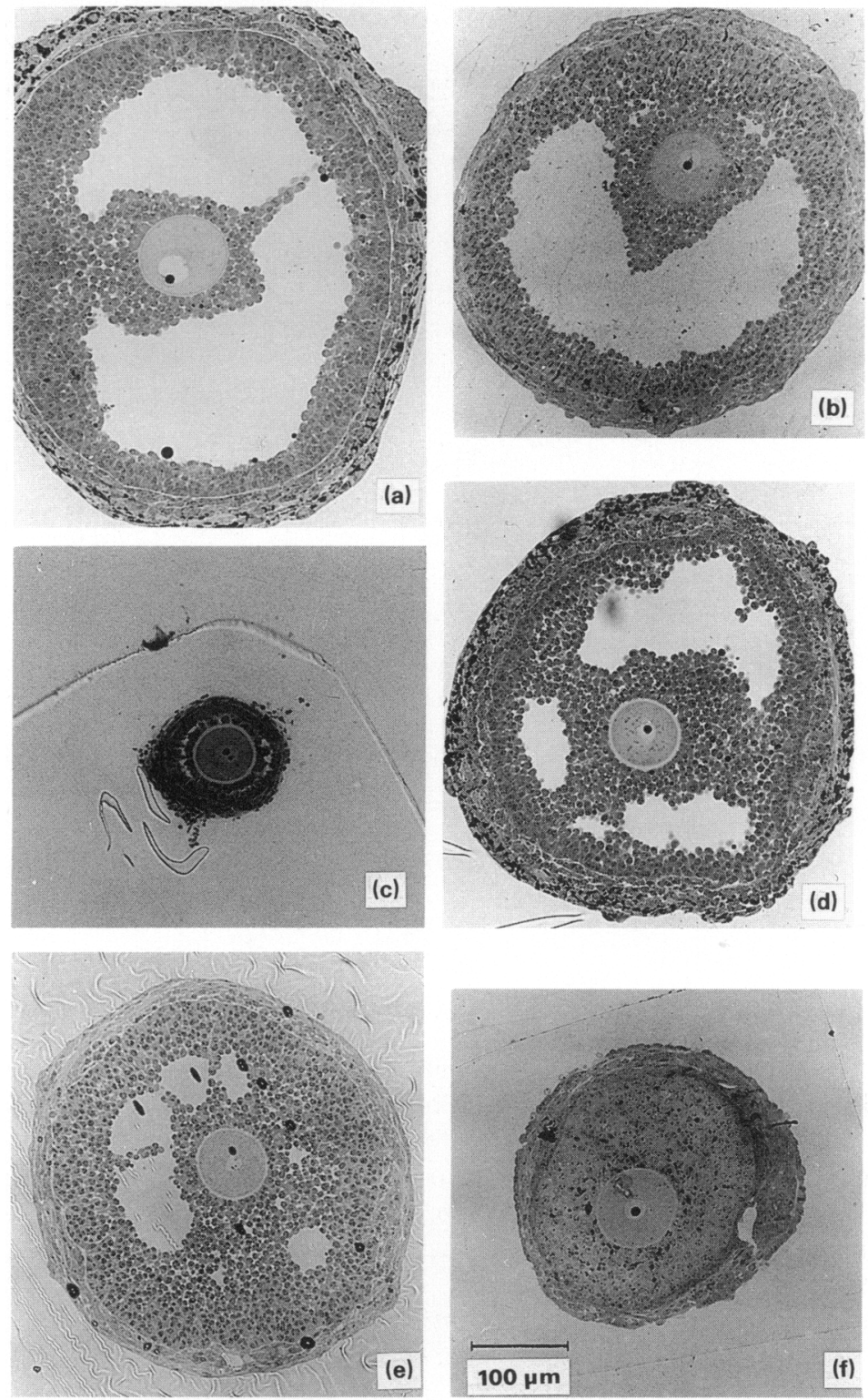

Fig. 7. Morphology of mouse follicles: ( $a$ and $b$ ) follicles that grew rapidly for 7 days in culture with 1000 miu human follicle-stimulating hormone $(\mathrm{hFSH}) \mathrm{ml}^{-1}$; these have full antra and normal appearance of oocyte well surrounded by cumulus cells, healthy granulosa and the presence of theca interna and externa; (c) follicle at start of culture for size comparison with follicles cultured for 7 days; ( $\mathrm{d}$ and e) follicles that grew more slowly and less normally with

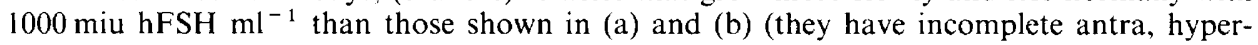
trophied theca and oocytes with patchy appearance); and (f) follicle after 7 days of culture lacking hFSH.

Two follicles grown with $1000 \mathrm{miu}$ hFSH ml ${ }^{-1}$ (Fig. 7d and e) but which did not grow as rapidly or as normally as those shown in Fig. 7a and b have a number of morphological characteristics which may be associated with early atresia. Some examples of these are an oocyte with 

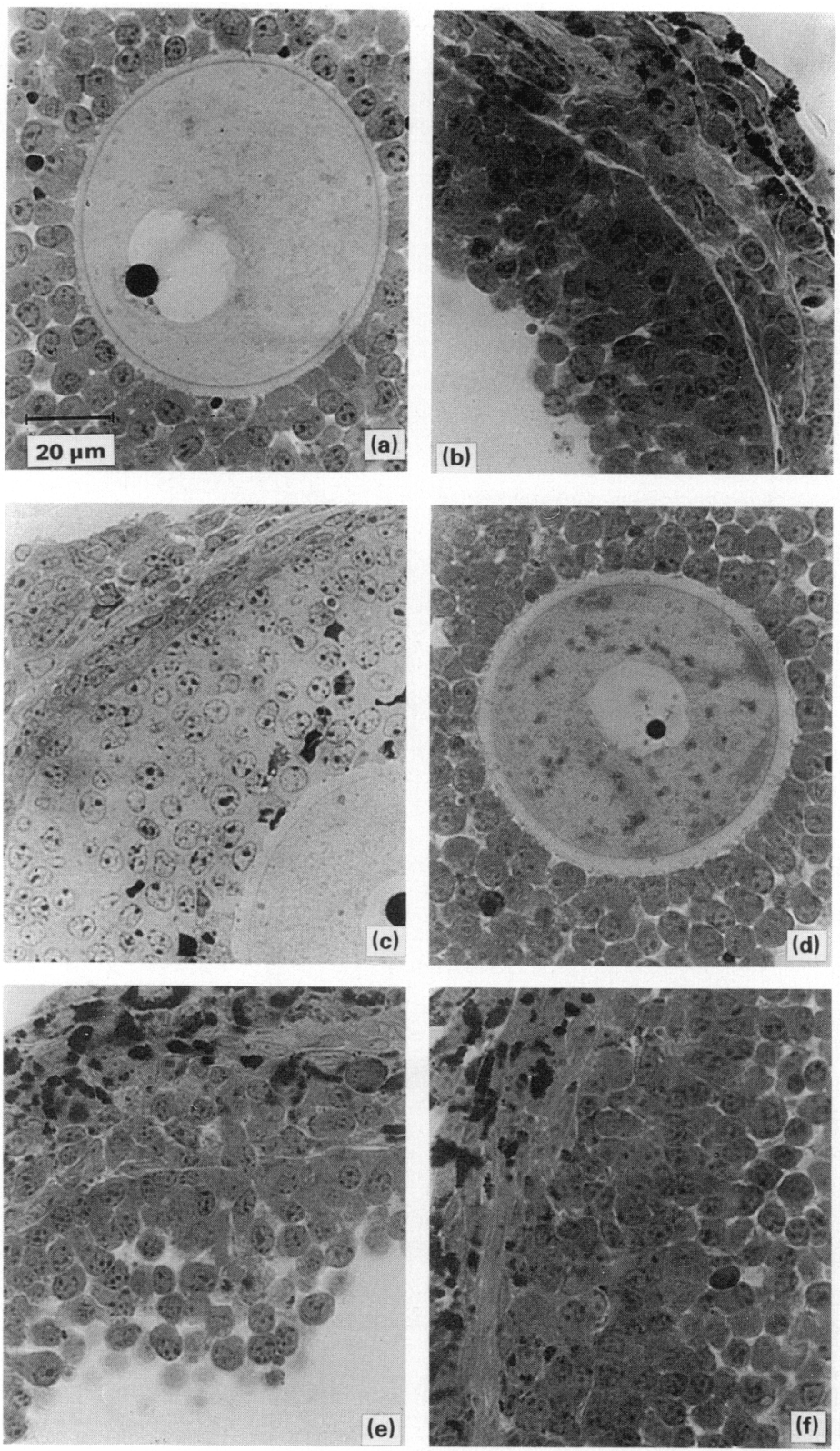

Fig. 8. Higher magnifications of follicles shown in Fig. 7: (a) oocyte and cumulus cells from large follicle in Fig. $7 \mathrm{a}$ - note even appearance of oocyte cytoplasm and healthy cumulus cells; (b) section of follicle wall, granulosa cells, and theca interna and externa from follicle in Fig. 7a, granulosa cells are well organized and healthy; theca interna and externa are present with an apparently normal appearance; and (c) details of oocyte, granulosa and theca from follicle grown without human follicle-stimulating hormone (from Fig. 7f). Examples of abnormalities of appearance from follicles that grew less rapidly in culture: (d) clumping of organelles in oocyte, (e) thin granulosa layer with less-ordered cell arrangement than in (b), and with a hypertrophied theca interna and (f) follicle wall indistinct and convoluted with hypertrophicd theca interna and excess of fibrous material in theca. 
organelle clumping (Fig. 8d), hypertrophied theca interna (Fig. 8e) and thin granulosa layer and an indistinct convoluted follicle wall with an abnormal theca interna and excess intercellular fibrous material between the theca externa and interna (Fig. 8f).

\section{Discussion}

Normal follicular development resulting in an oocyte capable of fertilization and embryonic development depends upon a complex sequence of cellular interactions within the follicle. These create a unique and progressively shifting environment for the development of the oocyte. At any stage during this development, the follicle may continue normally or, more frequently, proceed towards atresia. To study the mechanisms involved, it is necessary to follow and influence the development of individual follicles in vitro. We have reported a method which makes this possible.

This study has demonstrated that apparently morphologically normal preovulatory-size follicles can be grown at a high frequency in vitro from individual healthy preantral follicles that are in transition from two to three granulosa layers (stage 4 in transition to 5a). This was the minimum size that would reliably produce high rates of growth in culture. Stage 5a may be a critical one, as Pederson (1970) has shown that the number of labelled mitoses increases dramatically in vivo at this time. The culture system is simple, comprising static incubation over a Millicel membrane with $5 \%$ homologous serum, FSH with a low concentration of LH and a simple combination of growth factors. Mice of 25 days old were used because they were expected to have a low concentration of circulating gonadotrophin (Dullaart et al., 1975) and, based on results from rats (Döhler \& Wuttke, 1974), a low oestradiol concentration. Human FSH was used in the culture because the $\mathrm{ED}_{50}$ steroidogenic capacity of human FSH was similar to that of rat FSH (Hsueh et al., 1983; Carlsson et al., 1985) and the clinical potential of a biologically meaningful and accurate bioassay based on follicle culture.

Growth of individual follicles in culture allows each follicle to be studied continuously and makes it possible to relate particular developmental characteristics to subsequent reproductive performance of the gamete, thereby defining normal follicular development more accurately. Morphological studies performed with follicles having different growth rates in culture showed a normal appearance for the largest follicles, similar to that expected for a preovulatory follicle not yet exposed to the LH surge. Those growing more slowly showed a range of abnormalities. This supports the findings of Nayudu (1991), in which the more rapidly growing follicles in human stimulated cycles appeared to have greater developmental potential.

The health and uniformity of the starting material was critical to the uniform growth of follicles, and the presence of differentiated thecal cells was a prerequisite for antral development. A limited range of follicle size was successful for growth in vitro in the present system. Follicles less than $125 \mu \mathrm{m}$ in diameter were often not dissected with an intact thecal layer and therefore could not proceed through antral development. Follicles greater than $175 \mu \mathrm{m}$ were frequently atretic because the mice were prepubertal and therefore not ovulatory.

A low percentage of homologous serum was required and growth with mouse serum was superior to that with fetal calf serum, or that achieved in the studies by Qvist et al. (1990) with a high proportion of human serum. Serum types other than these two have not yet been exhaustively tested by us, but our results with mouse serum are similar to those of Sanyal \& Naftolin (1983), who found that inclusion of rat serum in post-implantation rat embryo culture was essential for normal development. Growth with BSA as the protein source consisted only of a mass of cells that proliferated, but did not maintain the follicle structure and secreted oestradiol earlier than the normal follicles. Mouse serum, therefore, must contain additional factors that are essential for the normal growth and differentiation of the follicle.

Although possible limiting factors in the culture system must be considered, differences in growth pattern of single and multiple follicles in the present study suggested that direct follicular 
communication may be important during development and may contribute to follicle selection. The inhibition of growth that occurred in our culture, and apparently in cultures reported by Qvist et al. (1990) where follicles were in direct contact with each other, could be a means of spacing the recruitable follicles in the ovary after oocyte growth is completed and when the major expansion of size commences. Where multiple follicles were grown in one well, but were not in contact, most tended to grow more slowly than the follicles cultured singly, but a small proportion grew much more rapidly than the others in the well. Such findings suggest that this system may be useful for examining the various hypotheses of follicle dominance.

Although the presence of hFSH is associated with only a small increase in the diameter of the follicles during in vitro preantral growth over that which occurs without the additional FSH (above that present in prepubertal mouse serum; Dullaart et al., 1975), the appearance of the follicles suggests that the density of granulosa cells is greater in the presence of FSH. This is consistent with the findings of Halpin et al. (1986) and de Reviers (1988), who have shown that follicles continue to grow in vivo from early preantral stages onward in gonadotrophin-deficient strains of mice, but in smaller numbers unless FSH is administered. FSH receptors are known to be present in granulosa cells and oocytes of small follicles (Mulheron et al., 1987), but FSH is apparently only one of several factors potentiating cell proliferation in small follicles.

In contrast to the situation for preantral growth, high concentrations of FSH are considered to be essential for antral development (Zeleznik \& Hillier, 1984), but our results suggest that a critical concentration of FSH during preantral growth is more important than the amount present after antral growth has been initiated. It is likely that the requirement for FSH is lower once normal antral growth is underway than for its initiation. The persistence of antral growth after FSH removal may be partially explained by the findings of Kim \& Greenwald (1986), who reported the persistence of FSH binding to its receptor in vivo for 4 days after hypophysectomy in hamsters. The question, however, of why slowly growing follicles depend on a high concentration of FSH for their continued growth, whereas rapidly growing follicles do not, remains to be investigated.

With fixed amounts of FSH in the culture, growth rate was positively related to the morphological normality of the follicles. Follicles which proceeded through antral development more slowly than others were found to have a range of abnormal characteristics in contrast to the rapidly growing follicles, which appeared similar to healthy in vivo follicles in midpro-oestrus before exposure to the LH surge. Further work is in progress to determine the functional normality of the oocytes from cultured follicles and to make more detailed morphological comparisons between follicles grown in vivo and in vitro. The more rapidly growing follicles also secreted higher concentrations of oestradiol than did the slowly growing ones. This variation among individual follicles in culture may be useful in understanding optimal follicle development and in analysing the mechanism of selection at different stages of growth. The steroid secretion of the cultured follicles was predominantly oestradiol, which was first detected with change of medium on day 4 and rose markedly on day 6 , and small amounts of progesterone, which rose only slightly during culture. The relative concentrations of oestradiol and progesterone on day 6 were consistent with those reported by Lieberman et al. (1975) for Graafian follicles explanted from pro-oestrous rats before the preovulatory gonadotrophin surge.

The dose-response curve for hFSH showed an increasing mean growth rate with increasing concentrations of FSH to a maximum of $100 \mathrm{miu} \mathrm{ml}^{-1}$. Doses of FSH from 250 to $2000 \mathrm{miu} \mathrm{ml}^{-1}$ did not cause further increases in antral-phase growth, although there was an indication that preantral growth rate was increased with $>100 \mathrm{miu}$ FSH ml ${ }^{-1}$. In marked contrast to this plateau in antral growth at $100 \mathrm{miu} \mathrm{ml}^{-1}$, oestradiol production, which was low on day 6 with $100 \mathrm{miu}$ FSH $\mathrm{ml}^{-1}$, continued to increase with increasing FSH up to the highest dose tested, $2000 \mathrm{miu} \mathrm{ml}^{-1}$. This is an important finding that was only detectable with individually cultured intact follicles. This lower FSH plateau for follicle growth remains to be investigated.

This study has shown that the follicle is a developmental unit, not requiring a blood vascular or a neural system for growth and development from preantral through to periovulatory stages, and a 
number of factors have been shown to influence the rate of growth and normality of development. The culture system described may be a useful and simple means for investigating some of the critical questions of follicular development.

This work was supported by Ares-Serono Inc., Boston, MA, USA. We are grateful to D. L. Hay (in memoriam), and his assistants N. Horwood and K. Oliva for carrying out the oestradiol and progesterone assays and to K. Grant of Edinburgh University for additional histology. We also wish to thank W. I. H. Johnston for his unwavering interest and faith in this project and R. G. Gosden of Edinburgh University for careful reading of the manuscript. P. L. Nayudu also wishes to acknowledge the support of the Wellcome Trust and the University of Edinburgh during the preparation of this manuscript.

\section{References}

Baker, T.G. \& Neal, P. (1974) Organ culture of cortical fragments and Graafian follicles from human ovaries. Journal of Anatomy 117, 361-371.

Bogovich, K. \& Richards, J.S. (1982) Androgen biosynthesis in developing ovarian follicles: evidence that luteinizing hormone regulates thecal $17 \alpha$-hydroxylase

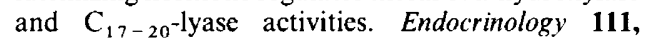
1201-1208.

Carlsson, B., Skanberg, J-O., Roos, P. \& Hillensjö, T. (1985) Comparison between the effects of FSH and LH on the steroidogenic pattern in isolated preovulatory rat follicles. Acta Endocrinologica 108, 557-564.

Carson, R.S., Zhang, Z., Hutchinson, L.A., Herington, A.C. \& Findlay, J.K. (1989) Growth factors in ovarian function. Journal of Reproduction and Fertility 85, 735-746.

de Reviers, M.M. (1988) Sequential effects of FSH on the first stages of ovarian follicular development in normal and dwarf Snell mice. Acta Endocrinologica 117, 26-32.

Döhler, K.D. \& Wuttke, W. (1974) Changes with age in levels of serum gonadotropins, prolactin, and gonadal steroids in prepubertal male and female rats. Endocrinology 97, 898-907.

Dullaart, J., Kent, J. \& Ryle, M. (1975) Serum gonadotrophin concentrations in infantile female mice. Journal of Reproduction and Fertility 43, 189-192.

Eppig, J.J. \& Downs, S.M. (1987) The effect of hypoxanthine on mouse oocyte growth and development in vitro: maintenance of meiotic arrest and gonadotropininduced oocyte maturation. Developmental Biology 119, 313-321.

Eppig, J.J. \& Schroeder, A.C. (1989) Capacity of mouse oocytes from preantral follicles to undergo embryogenesis and development to live young after growth, maturation, and fertilization in vitro. Biology of Reproduction 41, 268-276.

Epstein-Almog, R. \& Orly, J. (1985) Inhibition of hormone-induced steroidogenesis during cell proliferation in serum-free cultures of rat granulosa cells. Endocrinology 116, 2103-2111.

Fukui, Y., Imai, K., Alfonso, N.F. \& Ono, H. (1987) Follicle culture enhances fertilizability and cleavage of bovine oocytes matured in vitro. Journal of Animal Science 64, 935-941.
Fukui, Y., Glew, A.M., Gandolfi, F. \& Moor, R.M. (1988) In vitro culture of sheep oocytes matured and fertilized in vitro. Theriogenology 29, 883-891.

Gore-Langton, R.E. \& Daniel, S.A.J. (1990) Folliclestimulating hormone and estradiol regulate antrumlike reorganization of granulosa cells in rat preantral follicle cultures. Biology of Reproduction 43, 65-72.

Goto, K., Kajihara, S., Kosaka, S., Koba, M., Nakanishi, Y. \& Ogawa, K. (1988) Pregnancies after co-culture of cumulus cells with bovine embryos derived from in-vitro fertilization of in-vitro matured follicular oocytes. Journal of Reproduction and Fertility 83, 753-758.

Halpin, D.M.G., Jones, A., Fink, G. \& Charlton, H.M. (1986) Postnatal ovarian development in hypogonadal (hpg) and normal mice and associated changes in the hypothalamic-pituitary ovarian axis. Journal of Reproduction and Fertility 77, 287-296.

Hogan, B., Costantini, F. \& Lacy, E. (1986) Manipulating the Mouse Embryo. A Laboratory Manual. Cold Spring Harbor Laboratory, Cold Spring Harbor, New York.

Hsueh, A.J.W., Erickson, G.F. \& Papkoff, H. (1983) Effect of diverse mammalian gonadotropins on estrogen and progesterone production by cultured rat granulosa cells. Archives of Biochemistry and Biophysics 225, 505-511.

Jia, X-C. \& Hsueh, A.J.W. (1986) Granulosa cell aromatase bioassay for follicle-stimulating hormone: validation and application of the method. Endocrinology 119, 1570-1577.

Kim, I. \& Greenwald, G.S. (1986) Occupied and unoccupied FSH receptors in follicles of cyclic, hypophysectomized or hypophysectomized/gonadotropin-treated hamsters. Molecular and Cellular Endocrinology 44, 141-145.

Laufer, N., Reich, R., Braw, R., Shenker, J.G. \& Tsafriri, A. (1982) Effect of clomiphene citrate on preovulatory rat follicles in culture. Biology of Reproduction 27, 463-471.

Lieberman, M.E., Barnea, A., Bauminger, S., Tsafriri, A., Collins, W.P. \& Lindner, H.R. (1975) LH effect on the pattern of steroidogenesis in cultured Graafian follicles of the rat: dependence on macromolecular synthesis. Endocrinology 96, 1533-1542.

McNatty, K.P., Makris, A., De Grazia, C., Osathanondh, R. \& Ryan, K.J. (1980) Steroidogenesis by recombined 
follicular cells from the human ovary in vitro. Journal of Clinical Endocrinology and Metabolism 51, 1286-1292.

Moor, R.M. \& Trounson, A.O. (1977) Hormonal and follicular factors affecting maturation of sheep oocytes in vitro and their subsequent developmental capacity. Journal of Reproduction and Fertility 49, 101-109.

Mulheron, G.W., Quattropani, S.L. \& Nolin, J.M. (1987) On the intrinsic ovarian control of the developmental transition from primordial to primary follicle. Advances in Experimental Medicine and Biology 219, 337-342.

Nayudu, P.L. (1991) Relationship of individual follicular growth patterns in stimulated cycles to outcome after IVF. Human Reproduction 6, 465-471.

Nayudu, P.L., Lopata, A., Jones, G.M., Gook, D.A., Bourne, H.M., Sheather, S.J., Brown, T.C. \& Johnston, W.I.H. (1989) An analysis of human oocytes and follicles from stimulated cycles: oocyte morphology and associated follicular fluid characteristics. Human Reproduction 4, 558-567.

Nekola, M.V. \& Nalbandov, A.V. (1971) Morphological changes of rat follicular cells as influenced by oocytes. Biology of Reproduction 4, 154-160.

Pederson, T. (1970) Determination of follicle growth rate in the ovary of the immature mouse. Journal of Reproduction and Fertility 21, 81-93.

Qvist, R., Blackwell, L.F., Bourne, H. \& Brown, J.B. (1990) Development of mouse ovarian follicles from primary to preovulatory stages in vitro. Journal of Reproduction and Fertility 89, 169-180.

Roy, S.K. \& Greenwald, G.S. (1989) Hormonal requirements for the growth and differentiation of hamster preantral follicles in long-term culture. Journal of Reproduction and Fertility 87, 103-114.
Sanyal, M.K. \& Naftolin, F. (1983) In vitro development of the mammalian embryo. Journal of Experimental Zoology 228, 235-251.

Schroeder, A.C. \& Eppig, J.J. (1984) The developmental capacity of mouse oocytes that matured spontaneously in vitro is normal. Developmental Biology $102,493-497$.

Staigmiller, R.N. \& Moor, R.M. (1984) Effect of follicle cells on the maturation and developmental competence of ovine oocytes matured outside the follicle. Gamete Research 9, 221-229.

Terada, N., Kuroda, H., Takatsuka, D., Matsumoto, K. \& Kitamura, Y. (1985) Effect of serum and 12-otetradecanoyl-phorbol-13-acetate on FSH-stimulated conversion of 4-androstene-3,17-dione to oestrogens in cell and organ cultures of suckling mouse ovaries. Journal of Steroid Biochemistry 22, 401-405.

Torrance, C., Telfer, E. \& Gosden, R.G. (1989) Quantitative study of the development of isolated mouse pre-antral follicles in collagen gel culture. Journal of Reproduction and Fertility 87, 367-374.

Vanhems, E., Bousquet, J. \& Valero, D. (1982) Événements morphologiques et biochimiques liés à la période périovulatoire de follicules ovariens de rattes. Annales d'Endocrinologie 43, 69-87.

Zeleznik, A.J. \& Hillier, S.G. (1984) The role of gonadotropins in the selection of the preovulatory follicle. Clinical Obstetrics and Gynecology 27, 927-940.

Zimmerman, R.C., Wun, W.-S., Tcholakian, R.K., Rodrigues-Rigau, L.J., Braendle, W. \& Steinberger, E. (1985) In vitro steroid secretion by intact bovine ovarian follicles in a superfusion system. Hormone and Metabolic Research 17, 458-463.

Received 18 March 1991 